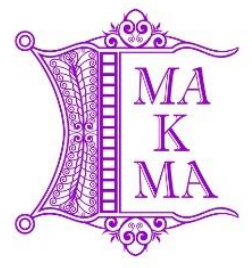

Majalah Kesehatan Masyarakat Aceh (MaKMA) http:/lojs.serambimekkah.ac.id/index.php/makma

\title{
ANALISIS PELAKSANAAN PROMOSI KESEHATAN TEMPAT KERJA DI PT SURI TANI PEMUKA BANYUWANGI
}

\section{Ayu Purwanti, Dian Nindia Yuliana, Nenda Puspita Sari}

Departemen Promosi Kesehatan dan Ilmu Perilaku, Program Studi Kesehatan Masyarakat PSDKU Universitas Airlangga, Banyuwangi.

${ }^{\bowtie}$ Alamat Korespondensi: Perum Permata Giri Banyuwangi. Email: ayupurwanti744@gmail.com. No Hp: 081334288463.

\begin{abstract}
ABSTRAK
Promosi kesehatan di tempat kerja (PKDTK) adalah suatu kegiatan di tempat kerja untuk merancang suatu program membantu tingkat pekerjaan di semua level, meningkatkan dan memperbaiki kesehatan pekerja dengan partisipasi pekerja, manajemen dan stake holder lainnya. Penelitian ini bertujuan untuk mengetahui gambaran pelaksanaan promosi kesehatan tempat kerja di PT Suri Tani Pemuka Banyuwangi. Metode yang digunakan adalah wawancara dan observasi. Wawancara dilakukan kepada seketaris P2K3 dilaksanakan di kantor perusahan dengan menggunakan panduan wawancara. Observasi yang dilakukan menggunakan instrumen yang di buat berdasarkan buku dan teori terkait persyaratan promosi kesehatan di tempat kerja. Observasi dimulai dari pos satpam, halaman depan, kantor, mushola, ruang produksi, gudang penyimpanan bahan, gudang penyimpanan pakan jadi. PT Suri Tani Pemuka memiliki peraturan atau kebijakan resmi mengenai kesehatan dan keselamatan kerja (tertulis). Biasanya peraturan atau kebijakan dicetak dan disebar luaskan di perusahaan dan setiap setahun sekali seluruh pekerja melakukan evalusi kerja, sehingga perusahaan mengetahui bagian mana saja yang masih belum tercapai agar tahun berikutnya dapat memperbaiki dan dapat mencapai target tersebut. Pelaksanaan promosi kesehatan di tempat kerja PT. Suri Tani Pemuka secara keseluruhan dalam kategori baik. Perusahan PT. Suri Tani Pemuka terus berinovasi dalam pelaksanaan promosi kesehatan di tempat kerja sebagai langkah peningkatan kesejahteraan karyawan seperti Poster kesehatan.
\end{abstract}

Kata Kunci: Pelaksanaan, Promosi Kesehatan, Tempat Kerja.

Riwayat Artikel

Diterima : 23 November 2018 


\title{
DESCRIPTION OF THE IMPLEMENTATION OF WORKPLACE HEALTH PROMOTION IN PT SURI TANI PEMUKA BANYUWANGI
}

\begin{abstract}
Workplace health promotion (PKDTK) is an activity in the workplace to design a program to help work at all levels, improve and improve the health of workers with the participation of workers, management and other stakeholders. This research aims to describe the implementation of workplace health promotion at PT Suri Tani Pemuka Banyuwangi. The method used is interview and observation. Interviews were conducted with P2K3 secretaries conducted at the company's office using interview guides. Observations made using instruments made based on books and theories related to health promotion requirements in the workplace. Observation starts from security post, front yard, office, production room, material storage warehouse, finished feed storage warehouse. PT Suri Tani Pemuka has official regulations or policies regarding occupational health and safety (written). Usually regulations or policies are printed and disseminated in the company and every year all workers carry out work evaluations, so the company knows which parts have not yet been achieved so that the following year they can improve and reach these targets. Implementation of health promotion at the workplace of PT. Suri Tani The overall leader is in a good category. PT. Suri Tani Pemuka continues to innovate in the implementation of health promotion in the workplace as a step to improve employee welfare such as health posters.
\end{abstract}

Keywords: Implementation, Health Promotion and Workplace. 


\section{PENDAHULUAN}

Tempat Kerja adalah tiap ruangan atau lapangan tertutup atau terbuka bergerak atau tetap di mana tenaga kerja bekerja atau yang sering dimasuki tenaga kerja untuk keperluan suatu usaha dan terdapat sumber atau sumbersumber bahaya sebagaimana diperinci dalam Pasal 2 Undang-Undang Nomor $1 \quad$ Tahun 1970 (PER.15/MEN/VIII/2008). Tempat kerja yang sehat adalah tempat di mana semua orang bekerja sama untuk mencapai visi yang disepakati kesehatan dan kesejahteraan pekerja dan masyarakat sekitar. Ini menyediakan semua anggota tenaga kerja dengan kondisi fisik, psikologis, sosial dan organisasi yang melindungi dan mempromosikan kesehatan dan keselamatan. Ini memungkinkan para manajer dan pekerja untuk meningkatkan kendali atas kesehatan mereka sendiri dan untuk memperbaikinya, dan menjadi lebih energik, positif dan puas. Sebagai imbalannya, tenaga kerja lebih banyak stabil, berkomitmen dan produktif ${ }^{(1)}$.

Konsep tempat kerja yang sehat menyediakan alat yang berharga untuk dikembangkan atau di perkuat standar kesehatan dan keselamatan kerja sehingga kondisi terus meningkat untuk bekerja populasi. Namun, tempat kerja yang sehat tidak hanya bebas dari bahaya, tetapi juga menyediakan sebuah lingkungan yang merangsang dan memuaskan bagi pekerja. Ada yang tumbuh penghargaan untuk berbagai faktor penentu kesehatan pekerja, termasuk lingkungan, organisasi (misalnya beban kerja, gaya manajemen dan komunikasi), masyarakat dan factor kemasyarakatan, serta gaya hidup pribadi. Organisasi yang sehat mengakui semua elemen ini dalam pengembangan kebijakan dan program untuk kesejahteraan para pekerjanya ${ }^{(2)}$. \begin{tabular}{lllr}
\multicolumn{2}{c}{ Tempat kerja yang sehat } \\
bertujuan & untuk & menciptakan \\
lingkungan & kerja & yang sehat
\end{tabular} mendukung dan aman, memastikan bahwa promosi kesehatan dan perlindungan kesehatan menjadi bagian integral dari manajemen praktek. Memupuk gaya kerja dan gaya hidup yang kondusif untuk kesehatan, memastikan total partisipasi organisasi. Dan memperluas dampak positif bagi masyarakat dan lingkungan setempat dan sekitar.

Program-program kesehatan, terutama yang terkait dengan pekerja perlu selalu disosialisasikan secara terus menerus, hal ini dikarena perubahan tingkah laku kadang hanya dapat terjadi dalam kurun waktu yang relatif lama. Dari pengalaman bertahun-tahun pelaksanaan promosi atau penyuluhan kesehatan masyarakat mengalami berbagai hambatan dalam rangka mencapai tujuannya, yaitu mewujudkan perilaku hidup sehat bagi pekerja, terutama bagi para pekerja di perkantoran $^{(3)}$.

Selama bertahun-tahun, WHO telah bekerja sama dengan Organisasi Perburuhan Internasional (ILO), lainnya lembaga mitra internasional dan Negara Anggota untuk meningkatkan kesehatan tenaga kerja melalui program kesehatan kerja. Pengenalan terbaru dari pendekatan "pengaturan sehat" WHO telah memberikan cahaya baru pada penerapan promosi kesehatan ke tempat kerja (PKDTK). Seperti pengaturan lain di mana WHO telah mengembangkan prakarsa yang mempromosikan kesehatan (sekolah, kota, rumah sakit dan pasar), tempat kerja dapat memiliki dampak yang sangat positif terhadap kesehatan dan kesejahteraan pekerja, keluarga mereka, komunitas dan masyarakat luas.

Menurut WHO (1999) PKDTK adalah berbagai aktifitas di tepat kerja 
yang di rancang untuk membantu tingkat pekerjaan dan perusahan di semua level, dan memperbaiki dan meningkatkan kesehatan dengan partisipasi pekerja, manajemen dan stake holder lainnya. Tujuan dari PKDTK adalah untuk memberikan informasi kesehatan dan meninngkatkan kemampuan pekerja untuk mengenali masalah kesehatan yang pontensial terjadi di dalam maupun diluar tempat kerja.

\section{METODE}

Penelitian ini adalah penelitian Kualitatif yang mendeskripsikan pelaksanaan Promosi Kesehatan Tempat Kerja di PT Suri Tani Pemuka Banyuwangi berdasarkan Regional Guidelines For Healthy Workplaces(WHO). Lokasi yang digumakan peneliatian ini pada PT Suri Tani Pemuka, Jl. Gatot Subroto No. 46, Bulusan Kalipuro Banyuwangi. Penelitian ini dilaksanakan pada tahun 2017. Penelitian ini menggunakan metode observasi yang di lakukan 2 kali observasi dan mengunakan metode wawancara mendalam ( in-depth interview). Wawancara mendalam dilakukan secara informal yang dilaksanakan di kantor perusahaan. Pihak yang diwawancarai adalah sekretasis P2K3. Hasil wawancara mendalam digunakan sebagai informasi utama yang diperlukan dan penunjang data observasi.

Observasi pertama dilakukan untuk melihat lingkungan sekitar perusahaan

\section{HASIL}

Berdasarkan Komponen Promosi Kesehatan di Tempat Kerja adalah (WHO (1999) Regional Guidelines For Healthy Workplaces).
Penelitian ini untuk mengetahui gambaran pelaksanaan promosi kesehatan tempat kerja di PT Suri Tani Pemuka Banyuwangi. Bertujuan untuk mengetahui dan mendeskripsikan komponen-komponen yang terkait dengan promosi kesehatan di tempat kerja PT Suri Tani Pemuka Banyuwangi apakah sudah terlaksana. Selanjutnya dapat diberikan rekomendasi atas hasil observasi yang dilakukan kepada PT Suri Tani Pemuka Banyuwangi.

mulai dari pos satpam, kantor perusahaan hingga pada ruang produksi. Observasi pertama dilakukan sebagai acuan pembuatan instrumen. Selain melihat keadaan fisik perusahaan, peneliti juga melakukan pencarian data sekunder PT. Suri Tani Pemuka kepada sekretaris P2K3. Observasi kedua dilakukan untuk menilai pelaksanaan promosi kesehatan di tempat kerja. Pengumpulan data menggunakan metode checklist instrumen yang telah peneliti susun. Observasi dimulai dari pos satpam, halaman depan, kantor, mushola, ruang produksi, gudang penyimpanan bahan, gudang penyimpanan pakan jadi, IPAL. Adapun komponen yang ada di instrumen adalah yang pertama kebijakan promosi kesehatan di tempat kerja. Kedua lingkungan sosial tempat kerja. Ketiga lingkungan fisik. Keempat gaya hidup dan keterampilan kesehatan personal. Dan yang terakhir adalah pelayanan kesehatan.

\section{Kebijakan Promosi Kesehatan di Tempat Kerja.}

Pada analisis kebijakan promosi kesehatn di tempat kerja terdapat 17 aspek yang diamati. Dari 17 aspek yang diamati ada tiga aspek yang belum terpenuhi yaitu Sistem Manajeman Kesehatan dan Keselamatan Kerja, 
alokasi anggaran untuk menjalankan program kesehtan dan kesehatan kerja, dan sistem informasi terkait kesahatan dan kesalamatan kerja. [ Tabel. 1 ]

2. Lingkungan Sosial Tempat Kerja

Pada lingkungan tempat kerja terdapat 10 aspek yang diamati. Pada hasil analisis lingkungan sosial tempat kerja ini semua aspek terpenuhi.

\section{[Tabel. 2 ]}

\section{Lingkungan Fisik}

Hasil observasi pada lingkungan fisik ada beberapa aspek yang belum terpenuhi yaitu belum ada poster cuci tangan, belum tersedianya ruang $\mathrm{P} 3 \mathrm{~K}$, buku panduan $\mathrm{P} 3 \mathrm{~K}$ dan belum ada kantin sehat di perusahan. [Tabel. 3]

\section{PEMBAHASAN}

PT Suri Tani Pemuka merupakan perusahaan yang bergerah dibidang perikanan dengan bidang usaha pakan udang dan pakan ikan yang berlokasi berada diwilayah Kecamatan Kalipuro. Kegiatan usaha pakan udang dan pakan ikan merupakan unit hasil pengembangan industri yang dirilis oleh PT. Suri Tani.

PT Suri Tani Pemuka memiliki program kesehatan dan keselamatan kerja namun masih belum memiliki SMK3 (Sistem Manajemen Kesehatan dan Keselamatan Kerja). Penempatan organisasi K3 berada pada posisi strategis dalam penentuan keputusan perusahaan. Terdapatnya visi misi dari program kesehatan dan keselamatan kerja.. PT Suri Tani Pemuka memiliki peraturan atau kebijakan resmi mengenai kesehatan dan keselamatan kerja (tertulis). Biasanya peraturan atau kebijakan dicetak dan disebar luaskan di perusahaan dan setiap setahun sekali seluruh pekerja melakukan evalusi kerja, sehingga perusahaan mengetahui bagian mana saja yang masih belum tercapai agar tahun berikutnya dapat memperbaiki dan dapat mencapai target
4. Gaya Hidup dan Keterampilan Kesehatan Personal

Pada gaya hidup dan keterampilan kesehatan personal terdapat 14 aspek yang diamati. Dari aspek yang diamati masih banyak yang belum terpenuhi salah salah satunya adalah belum ada pelayanan konseling di perusahaan. [ Tabel. 4]

\section{Pelayanan Kesehatan}

Pada hasil wawancara pelaksanaan pelayanan kesehatan di lakukan oleh perusahan adalah berkerja sama dengan layanan kesehatan setempat untuk membuat program tempat kerja yang sehat.[Tabel. 5]

tersebut. Hal ini diperkuat dengan hasil wawancara, yang menjelaskan: "Peraturan atau kebijakan dicetak dan disebar dengan setiap bulannya di bacakan mengenai kebijakan K3". Pada perusahaan ini juga terdapat evaluasi program kesehatan dan keselatan kerja, evaluasi ini juga dilakukan satu tahun sekali.

PT Suri Tani Pemuka telah membentuk P2K3 (Panitia Pembina Kesehata dan Keselatan Kerja) dan selalu melakukan pertemuan rutin yaitu satu bulan sekali. Pertemuan rutin ini dilakukan dengan semua departemen namun biasanya perwakilan dari setiap departemen tersebut, jadi tidak semua P2K3 ikut dalam pertemuan rutin tersebut. Namun biasanya terdapat jadwal tersendiri di setiap departemennya agar yang mengikuti pertemuan rutin tersebut tidak hanya satu orang saja, namun semua secara bergilir mengikuti pertemuan rutin itu. Hal ini diperkuat dengan hasil wawancara, yang menjelaskan: "Setiap perbulannya ada pertemuan $P 2 K 3,1$ bulan sekali, itu dengan semua departemen pasti ada perwakilan per departemen". Pada perusahaan ini 
terdapat susunan program atau rencana kerja dari petugas P2K3. Setiap pertemuan rutin $\mathrm{P} 2 \mathrm{~K} 3$ yang dibahas adalah hasil monitoring dari program kerja yang telah direncanakan oleh P2K3, agar di akhir tahun dapat merencanakan susunan program atau rencana kerja yang masih belum tercapai dan yang masih akan direncanakan lagi serta inovasinya. Pada susunan program atau rencana kerja masih belum mengalokasikan anggaran untuk menjalankan program kesehatan dan keselamatan kerja. Jika pada minggu ini membutuhkan untuk menganggarkan poster maka pada minggu itu juga dianggarkan karena biasanya dalam satu tahun tersebut alokasi anggaran program kesehatan dan keselatan kerja sama sekali tidak terpakai maka perusahaan lebih memilih tidak mengalokasikan tersendiri namun jika membutuhkan langsung dianggarkan dan masuk dalam evaluasi kerja tahunan. Perusahaan memiliki kebijakan tentang jaminan kesehatan pada karyawan dengan mendaftarkan para pekerja pada BPJS Kesehatan dan BPJS Ketenagakerjaan agar setiap pekerja memiliki jaminan kesehatan.

PT Suri Tani Pemuka telah memiliki deskripsi pekerjaan atau jobsdesk yang jelas dan tertulis pada pekerjanya. Sehingga para pekerja tidak ada yang double jobsdesk dan telah memiliki pekerjaan sendiri-sendiri. Karena untuk meminimalkan risiko terjadinya kecelakaan kerja di perusahaan. Jika ada seorang pekerja yang memiliki jobsdesk lebih dari satu maka perusahaan akan segera mencari pengganti atau memberikan pada orang lain pekerjaan tersebut. Pada perusahaan ini manajer memotivasi pekerjanya mengenai kesehatan dan keselamatan kerja, agar pekerjanya selalu mengenakan APD dan selalu mematuhi peraturan kesehatan dan keselamatan kerja pada saat bekerja maupun pada saat tidak bekerja. Pada perusahaan ini adanya pengendalian pada pekerja yang merokok seperti jika ada seorang pekerja yang merokok maka akan segera ditegur dan menunjukkan area untuk merokok, bahwa hanya boleh merokok di area merokok saja. Dalam perusahaan sudah tersedia musik kerja namun masih belum berjalan efektif karena masih dalam tahap uji coba dan masih belum tersedia secara menyeluruh seperti sound di tempat kerja. Hal ini diperkuat dengan hasil wawancara, yang menjelaskan: "Kemarin sebenarnya sudah saya usulin tapi masih belum berjalan, baru 1 kali aja dibunyiin dan belum aktif'.

Pada perusahaan ini terdapat kegiatan untuk mengembangkan atau merekatkan hubungan dengan sesama karyawan dan manajer. Kegiatan tersebut dilakukan satu tahun sekali, biasanya kegiatan ini juga ada evalusinya namun ini seperti evaluasi pekerjanya. Kegiatan ini dilakukan di luar maupun di dalam perusahaan sendiri namun lebih sering dilakukan di luar perusahaan agar tidak bosan hanya di dalam perusahaan saja. Kegiatan tersebut biasanya berupa gatering dan outbond. Dalam serangkaian kegiatan tersebut biasanya adanya penghargaan pada karyawan yang berprestasi dan yang selalu patuh pada peraturan kesehatan dan keselamatan kerja di perusahaan.

PT Suri Tani Pemuka memiliki ventilasi udara diruang kerja sekitar $15 \%$ dari luas lantai, tidak hanya pada ruang kantor saja namun juga ruang produksi dan ruang penyimpanan. Suhu ruang didalam ruangan kantor mencapai $18-28^{\circ} \mathrm{C}$ dan di ruang produksi juga tidak lebih dari $28^{\circ} \mathrm{C}$. Kelembapan ruangan pada kantor juga hanya berkisar antara 40-60\% saja. Kebisingan 
pada tempat kerja tidak melebihi 85 dBA dan karyawan dengan kebisisngan yang tinggi diharapkan selalu menggunakan ear plug agar tidak sampai merusak telingan pekerja. Lantai dalam perusahaan kedap air dan selalu dalam keadaan kering, tidak ada genangan air namun lantai sedikit licin karena untuk mempermudah proses pengangkutan. Pencahayaan didalam dan diluar gedung industri sekitar 201500 lux tergantung ada tingkat ketelitian pekerjaan. Semakin teliti suatu pekerjaan maka semakin tinggi pula tingkat pencahayaan yang dibutuhkan pekerja dalam bekerja. Namun biasanya diluar gedung hanya menggunakan sinar matahari dan tanpa bantuan lampu lagi. Luas ruangan pada perusahaan yang memadai pada karyawan (setiap karyawan mendapatkan ruang udara minimal 10 $\mathrm{m}^{3} /$ karyawan), dan ruangan kerja bersih tidak ada sampah berserakan sama sekali. Didalam maupun diluar gedung perusahaan terdapat APAR dan APAR tersebut berada di tempat yang mudah terlihat sehingga mempermudah pekerja untuk menjangkau APAR tersebut.

PT Suri Tani Pemuka memiliki tempat sampah di setiap ruang dan setiap sudut perusahaan sehingga mempermudah pekerja untuk membuang sampah. Tempat sampah di perusahaan ini merupakan tempat sampah dengan bahan yang kuat dan juga ringan, sehingga mempermudah petugas kebersihan untuk mengangkut sampah dan memindahkan tempat sampah. Namun tempat sampah yang digunakan didalam dan diluar gedung berbeda, didalam gedung tempat sampah tertutup dan kedap air sedangkan tempat sampah yang berada diluar gedung tempat sampah yang terbuka namun juga kedap air. Sampah pada perusahaan ini setiap hari diangkut sehingga sampah tidak menjadi tempat perindukan vektor mampun rodent. Tempat sampah diperusahaan telah memisahkan antara sampah anorganik, organik serta sampah B3.

Toilet dalam perusahaan ini sudah terpisahkan antara laki-laki dan perempuan. Letak toilet juga mudah dijangkau oleh pekerja. Jumlah toilet juga telah memadai namun tidak tahu berapa pastinya jumlah toilet di PT Suri Tani Pemuka ini. Toilet juga memiliki air bersih yang mengalir namun tidak hanya di toilet saja namun juga ada di beberapa titik perusahaan. Dalam toilet juga terdapat tempat cuci tangan. Tempat cuci tangan tersebut terdapat air mengalir dan sabun serta terdapat tissu/alat pengering di samping cuci tangan. Namun di tempat cuci tangan belum terdapat poster cuci tangan seperti langkah cuci tangan dan manfaat cuci tangan.

PT Suri Tani Pemuka masih belum memiliki tempat istirahat untuk pekerja karena masih belum adanya tempat untuk tempat khusus istirahat pekerja. Namun pekerja biasanya istirahat di ruang tunggu dan dikantor pos satpam karena di tempat tersebut terdapat tempat duduk. Pada perusahaan ini memiliki kotak p3k disetiap ruangan dan setiap sudut tempat kerja namun masih belum tersedianya tempat khusus untuk p3k. Buku panduan mengenai p3k masih belum tersedia karena masih dalam proses pemesanan dan masih dalam proses percetakan. Karena buku mengenai panduan $\mathrm{P} 3 \mathrm{~K}$ harus tersedia di kotak P3K agar semua dapat melakukan pertolongan pertama ketika ada suatu kecelakaan. Hal ini diperkuat dengan hasil wawancara, yang menjelaskan: "Kemarin itu kita sudah mesen namun masih belum jadi, tapi sudah pesen masih dalam proses".

PT Suri Tani Pemuka masih belum tersedianya kantin sehat karena kantin perusahaan masih menjadi satu 
dengan kantin perusahaan PT Iroha. Pada perusahaan PT Suri Tani Pemuka memang masih belum menyediakan kantin perusahaan karena disekitar perusahaan banyak yang menjual makanan dan pada saat istirahat kebanyakan pekerja lebih memilih pulang dan makan siang di rumah mereka masing-masing. Karena banyak pekerja yang rumahnya berasa disekitar perusahaan tersebut, sehingga banyak yang memilih pulang ke rumah mereka masing-masing.

Pada perusahaan telah memiliki area untuk merokok dan tempat tersebut merupakan tempat terbuka sehingga terpisah dengan tempat kerja. Letak area merokok perusahaan berada di bawah pohon dekat dengan tempat parkir. Pada area merokok juga disediakan tempat sampah khusus putung rokok dan juga tempat sampah untuk sampah anorganik lainnya. Hal ini diperkuat dengan hasil wawancara, yang menjelaskan: "Iya ada, d belakang ada, di depan deket tempat parkir ada, trus di depan gudang ada, di depan produksi”.

Perusahaan juga mengaudit kesehatan dari semua bangunan, pabrik, dan peralatan di perusahaan untuk memastikan bahwa karyawan aman dari bahaya dan untuk meminimalisir terjadinya kecelakaan maupun penyakit akibat kerja. Perusahaan memiliki sarana ibadah seperti adanya mushola kecil dalam perusahaan, namun mushola tersebut terletak di belakang kantor sehingga banyak orang yang masuk perusahaan tidak mengetahui letak mushola namun terdapat petunjuk arah mushola. Pada perusahaan ini masih belum tersedia sarana untuk mengelola limbah padat non B3 namun perusahaan hanya mengelola air limbah saja yaitu dengan IPAL. Hal ini diperkuat dengan hasil wawancara, yang menjelaskan: "Kita disini hanya menyediakan limbah IPAL (instalasi pengelolaan air limbah) air sama limbah b3nya cuman TPS saja, kita gak ngolah". Limbah padat non B3 di buang dan di masukkan dalam TPA di daerah Bulusan.

PT Suri Tani Pemuka memiliki kegiatan pendidikan dan pelatihan terkait dengan gaya hidup sehat namun masih belum rutin dilakukan karena banyak karyawan yang tidak mengikuti kegiatan tersebut sehingga perusahaan hanya mengadakan pada saat terdapat pekerja baru namun perusahaan masih belum menyediakan pelayanan konseling untuk karyawan terkait dengan gaya hidup sehat. Pada perusahaan ini memiliki program manajemen stress pada karyawan dan program ini biasanya terserah dari pekerjanya cara menghilangkan stressnya. Cara menghiangkan stres pada pekerja, pekerja biasanya mendengarkan musik.

PT Suri Tani Pemuka masih belum menyediakan untuk upaya pencegahan dan pengendalian vektor, namun petugas kebersihan sebisa mungkin tidak adanya genangan air agar tidak menjadi tempat perindukan vektor. Tenaga khusus untuk pencegahan dan pengendalian vektor serta binatang pembawa penyakit masih belum ada dan hanya ada petugas kebersihan saja. Lain halnya dengan pengendalian rodent, pengendalian rodent pada perusahaan ini telah dilaksanakan karena pada gudang penyimpanan masih banyak rodent. Pada setiap sudut gudang penyimpanan telah tersedia sebuah kotak dan kotak tersebut untuk mengetahui bahwa terdapat rodent disekitar gudang penyimpanan tersebut.

PT Suri Tani Pemuka tidak memiliki program untuk menjaga kesehatan pada karyawan wanita karena jumlah karyawan yang relatif sedikit sehingga program yang ada hanya 
secara umum tidak ada yang spesifik. Pada perusahaan ini tidak memiliki ruang tertutup untuk menyusui dan memerah ASI beserta fasilitas didalamnya karena jumlah karyawan perempuan yang sedikit sehingga fasilitas untuk perempuan jugalah sedikit. Hal ini diperkuat dengan hasil wawancara, yang menjelaskan: "Dulu sih ada, nah skrang tidak difungsikan lagi, karena hampir 90\% karyawannya laki-laki dan tidak berjalan optimal". Namun untuk ibu yang bekerja dalam perusahaan ini boleh mengantarkan ASI ke anaknya namun hanya pada saat jam istirahat saja, setelah itu tidak boleh karena dapat menggangu dalam bekerja. Hal ini diperkuat dengan hasil wawancara, yang menjelaskan: "Kan ada jam istirahat, kadang-kadang ada yang pulang, lalu mompa dulu lalu diberikan pada anaknya".

PT Suri Tani Pemuka masih belum ada upaya dalam pencegahan dan penanggulangan HIV/AIDS di tempat kerja karena pada perusahaan tersebut tidak ada yang pernah terkena penyakit itu, jika ada yang mengidap penyakit tersebut mungkin pekerja akan berhenti dan tidak mau bekerja di perusahaan tersebut. Perusahaan ini juga masih belum ada program untuk mencegah penyalahgunaan dan peredaran gelap narkotika, psikotropika dan zat adiktif lainnya di tempat kerja karena menganggap itu sudah banyak di internet dan diyakini di daerah tersebut tidak terdapat peredaran narkotika, psikotropika dan zat adiktif lainnya. Didalam perusahaan terdapat label mengenai peringatan (B3) dan terdapat poster (larangan merokok, dll) di dalam perusahaan.

PT Suri Tani Pemuka masih belum menyediakan pelayanan kesehatan dasar dan juga medical check up secara periodik untuk seluruh karyawan serta tidak menyediakan pemeriksaan kesehatan yang tepat seperti penglihatan, pendengaran, dan lain-lain. Hal ini diperkuat dengan hasil wawancara, yang menjelaskan: "Medical check up dari mereka sendiri, perusahaan memiliki kerja sama dengan dokter, untuk karyawan yang ingin memeriksa diri. Jadi kalau sakit, iya periksa kesana sendiri perusahaan hanya merekomendasikan saja". Perusahaan hanya merekomendasikan dokter mana atau fasilitas kesehatan apa yang harus didatangi oleh karyawan. Perusahaan masih belum melembagakan kebijakan keseteraan gender di tempat kerja untuk melindungi dan mendukung perempuan atau kebijakan perlindungan bagi kelompok rentan lainnya dan perusahaan ini hanya sedikit memiliki pekerja perenpuan. Perusahaan tidak bekerja sama dengan layanan kesehatan namun hanya pada tenaga kesehatan seperti dokter untuk merujuk pekerja agar memeriksakan kesehatannya, dan itupun jika hanya pekerja telah merasakan gejala dari penyakit tersebut.

PT Suri Tani Pemuka tidak menyediakan tranportasi untuk antar jemput ke tempat kerja karena kebanyakan pekerja yang bekerja di PT Suri Tani Pemuka hanya tinggal disekitar perusahaan. Perusahaan hanya memberikan uang tranportasi pada karyawan. Uang tranportasi pada karyawan ini diberikan pada saat pekerja diberikan uang gaji setiap bulannya. Perusahaan ini masih tidak memiliki peraturan sendiri namun hanya ada peraturan yang secara umum, yaitu Dokumen Upaya Pengelolaan Lingkungan dan Upaya Pemantauan Lingkungan Hidup (UKL-UPL) yang merupakan salah satu bentuk pelaksanaan ketentuan perundangan yaitu Undang Undang Nomor 27 Tahun 2012 tentang Izin Lingkungan. Yang kemudian ditindak lanjuti dengan 
laporan rutin 6 (enam) bulanan ini sesuai ketentuan Kep.Men.LH No.45 Tahun 2005. Perusahaan ini telah memiliki AMDAL/ANDAL di perusahaan karena setiap perusahaan wajib memilikinya walaupun

\section{KESIMPULAN DAN SARAN}

Pelaksanaan promosi kesehatan di tempat kerja PT. Suri Tani Pemuka secara keseluruhan sudah baik berdasarkan hasil observasi dan wawancara yang telah dilakukan di PT. Suri Tani Pemuka sudah memenuhi kriteria undang-undang promosi kesehatan di tempat kerja. Mulai dari kebijakan promosi kesehatan di tempat kerja, lingkungan sosial tempat kerja, lingkungan fisik, gaya hidup dan keterampilan kesehatan personal, pelayanan kesehatan serta dampak terhadap lingkungan eksternal.

\section{DAFTAR PUSTAKA}

1. ILO.Kesehatan dan Keselamatan Kerja Sarana Untuk Produktif. Edisi bahasa Indonesia. Jakarta: 2013.

2. Peraturan Menteri Tenaga Kerja dan Transmigrasi Republik Indonesia Nomor : PER.15/MEN/VIII/2008 Tentang Pertolongan Pertama pada Kecelakaan di Tempat Kerja.

3. World Health Organization Regional Office For the Western Pacific. 1999. Regional Guidelines For the Development of Healthy Workplace.

4. Indah Lestari, Martina dan Yusuf Effendi.2005. Himpunan Peraturan Perundangan Keselamatan dan Kesehatan Kerja : PortalK3.com. perusahaan masih akan dibangun. Hal ini diperkuat dengan hasil wawancara, yang menjelaskan: "Kita bikin sendiri, dalam bentuk hardfile, kan juga setiap perusahaan harus ada AMDAL/ANDAL mbak sebelum mendirikan perusahaan"

Saran : PT. Suri Tani Pemuka diharapkan untuk meningkatkan kinerja mengenai pelaksanaan promosi kesehatan di tempat kerja yang sudah dilaksanakan, seperti menambahkan mengenai poster kesehatan dan poster mengenai penyakit yang ditimbulkan akibat kerja. Serta terus berinovasi dalam pelaksanaan promosi kesehatan di tempat kerja sebagai langkah peningkatan kesejahteraan karyawan PT. Suri Tani Pemuka.

5. Menteri Kesehatan RI. 2002. "Keputusan Menteri Kesehatan Republik Indonesia Tentang Persyaratan Kesehatan Lingkungan Kerja Perkantoran dan Industri Nomor 1405/MENKES/SK/XI/2002".

6. Notoatmodjo, S. 2007. Promosi Kesehatan: Teori dan Aplikasi. Jakarta:Rineka cipta

7. Peraturan Menteri Kesehatan Republik Indonesia nomor 48 tahun 2016 Tentang Standar Keselamatan dan Kesehatan Kerja Perkantoran.

8. Peraturan Menteri Kesehatan Republik Indonesia Nomor 70 Tahun 2016 Tentang Standar dan Persyaratan Kesehatan Lingkungan KerjaIndustri 


\section{LAMPIRAN}

Tabel. 1 Kebijakan Promosi Kesehatan di Tempat Kerja.

Penilaian Kebijakan Promosi Kesehatan Di Tempat Kerja di PT Suri Tani Pemuka

Keberadaan

Aspek yang diamati

\begin{tabular}{|c|c|c|}
\hline Aspek yang diamati & Ada & Tidak ada \\
\hline Terdapat Program kesehatan dan keselamatan kerja & $\sqrt{ }$ & \\
\hline $\begin{array}{l}\text { Terdapat SMK3 (Sistem Manajeman Kesehatan dan Keselamatan } \\
\text { Kerja) }\end{array}$ & & $\sqrt{ }$ \\
\hline $\begin{array}{l}\text { Penempatan organisasi K3 pada posisi strategis dalam penentuan } \\
\text { keputusan perusahaan }\end{array}$ & $\sqrt{ }$ & \\
\hline $\begin{array}{l}\text { Terdapat visi misi dari program kesehatan dan kesalamatan tempat } \\
\text { kerja }\end{array}$ & $\sqrt{ }$ & \\
\hline $\begin{array}{l}\text { Memiliki peraturan atau kebijakan resmi mengenai kesehatan dan } \\
\text { keselamatan kerja (tertulis) }\end{array}$ & $\sqrt{ }$ & \\
\hline Terdapat perencanaan $\mathrm{K} 3$ & $\sqrt{ }$ & \\
\hline Terdapat Evaluasi Program kesehatan dan keselamatan kerja & $\sqrt{ }$ & \\
\hline Mengindetifikasi kondisi tempat kerja & $\sqrt{ }$ & \\
\hline $\begin{array}{l}\text { Mengidentifikasi sumber bahaya yang berkaitan dengan kegiatan } \\
\text { perusahaan }\end{array}$ & $\sqrt{ }$ & \\
\hline Menilai efisiensi dan efektifitas sumberdaya yang tersedia & $\sqrt{ }$ & \\
\hline Memiliki peraturan larangan merokok di area kantor & $\sqrt{ }$ & \\
\hline Terdapat P2K3 (Panitia Pembina Kasehatan dan Keselamatan Kerja) & $\sqrt{ }$ & \\
\hline Terdapat pertemuan rutin antara anggota $\mathrm{P} 2 \mathrm{~K} 3$ & $\sqrt{ }$ & \\
\hline Terdapat susunan Program atau rencana kerja dari petugas P2K3 & $\sqrt{ }$ & \\
\hline $\begin{array}{l}\text { Memiliki alokasi anggaran untuk menjalankan Program kesehatan } \\
\text { dan keselamatan kerja. }\end{array}$ & & $\sqrt{ }$ \\
\hline Terdapat kebijakan tentang jaminan kesehatan pada karyawan & $\sqrt{ }$ & \\
\hline Terdapat sistem informasi terkait kesahatan dan kesalamatan kerja. & & $\sqrt{ }$ \\
\hline
\end{tabular}

Sumber: Data Primer 2018 
Tabel. 2 Lingkungan Sosial Tempat Kerja

Penilaian Lingkungan Sosial Tempat Kerja di PT Suri Tani Pemuka

\begin{tabular}{lll}
\hline \multicolumn{1}{c}{ Aspek yang diamati } & Keberadaan \\
\cline { 2 - 2 } & Ada & Tidak ada \\
\hline $\begin{array}{l}\text { Karyawan memiliki Deskripsi pekerjaan atau jobdesk yang jelas } \\
\text { (tertulis) }\end{array}$ & $\sqrt{ }$ \\
$\begin{array}{l}\text { Terdapat motivasi dari manajer terkait Kesehatan dan keselamatan } \\
\text { kerja pada karyawan }\end{array}$ & $\sqrt{ }$ \\
$\begin{array}{l}\text { Ada kegiatan untuk mengembangkan atau merekatkan hubungan baik } \\
\text { sesama karyawan dan manajer }\end{array}$ & $\sqrt{ }$ \\
Ada penghargaan pada karyawan yang prestasi & $\sqrt{ }$ \\
$\begin{array}{l}\text { Ada penghargaan pada karyawan yang patuh pada peraturan kesehatan } \\
\text { dan keselamatan kerja }\end{array}$ & \\
Terdapat pengendalian pada karyawan yang merokok & $\sqrt{ }$ \\
$\begin{array}{l}\text { Tersedia musik kerja untuk membangkitkan semangat kerja yang } \\
\text { diperdengarkan pada saat akan memulai kerja dan sesaat sebelum } \\
\text { pulang }\end{array}$ & $\sqrt{ }$ \\
$\begin{array}{l}\text { Karyawan memiliki Deskripsi pekerjaan atau jobdesk yang jelas } \\
\text { (tertulis) }\end{array}$ & $\sqrt{ }$ \\
$\begin{array}{l}\text { Terdapat motivasi dari manajer terkait Kesehatan dan keselamatan } \\
\text { kerja pada karyawan }\end{array}$ & $\sqrt{ }$ \\
$\begin{array}{l}\text { Ada kegiatan untuk mengembangkan atau merekatkan hubungan baik } \\
\text { sesama karyawan dan manajer }\end{array}$ & $\sqrt{ }$ \\
\hline Sumb: & \\
\end{tabular}

Sumber: Data Primer 2018 
Tabel. 3 Lingkungan Fisik

Penilaian Lingkungan Fisik Tempat Kerja di PT Suri Tani Pemuka

\begin{tabular}{|c|c|c|}
\hline \multirow{2}{*}{ Aspek yang diamati } & \multicolumn{2}{|c|}{ Keberadaan } \\
\hline & Ada & Tidak ada \\
\hline Penyedian APAR & $\sqrt{ }$ & \\
\hline Terdapat tempat sampah di setiap ruangan & $\sqrt{ }$ & \\
\hline $\begin{array}{l}\text { Tersedia air bersih yang dipergunakan untuk keperluan sehari-hari } \\
\text { (tidak berwarna dan tidak berbau) }\end{array}$ & $\sqrt{ }$ & \\
\hline Toilet karyawan wanita dan pria terpisah & $\sqrt{ }$ & \\
\hline Jumlah 1 toilet maximal untuk 15 karyawan & $\sqrt{ }$ & \\
\hline Terdapat tempat cuci tangan (air mengalir dan sabun) & $\sqrt{ }$ & \\
\hline Terdapat poster cuci tangan (langkah cuci tangan) & & $\sqrt{ }$ \\
\hline Tersedia P3K di tempat kerja & $\sqrt{ }$ & \\
\hline Tersedia Ruang P3K & & $\sqrt{ }$ \\
\hline Terdapat buku panduan P3K & & $\sqrt{ }$ \\
\hline Terdapat kantin sehat & & $\sqrt{ }$ \\
\hline $\begin{array}{l}\text { Melakukan audit kesehatan dari semua bangunan, pabrik dan peralatan } \\
\text { untuk memastikan bahwa karyawan aman dari bahaya }\end{array}$ & $\sqrt{ }$ & \\
\hline
\end{tabular}


Tabel. 4 Gaya Hidup dan Keterampilan Kesehatan Personal

Penilaian Gaya Hidup dan Keterampilan Kesehatan Personal di PT Suri Tani Pemuka

\begin{tabular}{|c|c|c|}
\hline \multirow{2}{*}{ Aspek yang diamati } & \multicolumn{2}{|c|}{ Keberadaan } \\
\hline & Ada & Tidak ada \\
\hline $\begin{array}{l}\text { Adanya kegiatan pendidikan dan pelatihan terkait gaya hidup yang } \\
\text { sehat }\end{array}$ & $\sqrt{ }$ & \\
\hline $\begin{array}{l}\text { Terdapat penghargaan pada karyawan yang menerapkan gaya hidup } \\
\text { sehat }\end{array}$ & $\sqrt{ }$ & \\
\hline $\begin{array}{l}\text { Menyediakan pelayanan konseling untuk karyawan untuk konsultasi } \\
\text { terkait gaya hidup sehat }\end{array}$ & & $\sqrt{ }$ \\
\hline Terdapat Program manajemen Stress pada karyawan & $\sqrt{ }$ & \\
\hline Tersedia upaya pencegahan pengendalian vector & & $\sqrt{ }$ \\
\hline Tersedia upaya pencegahan pengendalian rodent & $\sqrt{ }$ & \\
\hline $\begin{array}{l}\text { Tersedia tenaga khusus untuk pencegahan dan pengendalian vector dan } \\
\text { binatang pembawa penyakit }\end{array}$ & & $\sqrt{ }$ \\
\hline $\begin{array}{l}\text { Terdapat program untuk menjaga kesehatan pada karyawan wanita } \\
\text { pada saat hamil }\end{array}$ & & $\sqrt{ }$ \\
\hline Terdapat ruang tertutup untuk menyusui dan memerah ASI & & $\sqrt{ }$ \\
\hline $\begin{array}{l}\text { Tersedia peralatan untuk menyimpan ASI dan peralatan pendukung } \\
\text { lainnya (lemari pendingin, meja dan kursi). }\end{array}$ & & $\sqrt{ }$ \\
\hline Tersedia tempat cuci tangan & & $\sqrt{ }$ \\
\hline $\begin{array}{l}\text { Adanya kesempatan ibu yang bekerja untuk memberikan ASI kepada } \\
\text { bayi selama waktu bekerja }\end{array}$ & $\sqrt{ }$ & \\
\hline $\begin{array}{l}\text { Adanya upaya pencegahan dan penanggulangan HIV/AIDS di tempat } \\
\text { kerja. }\end{array}$ & & $\sqrt{ }$ \\
\hline $\begin{array}{l}\text { Terdapat program untuk mencegah penyalahgunaan dan } \\
\text { peredaran gelap narkotika, psikotropika dan zat adiktif lainnya di } \\
\text { tempat kerja }\end{array}$ & & $\sqrt{ }$ \\
\hline $\begin{array}{l}\text { Terdapat label peringatan (B3) dan poster (larangan merokok, dll) di } \\
\text { perusahaan }\end{array}$ & $\sqrt{ }$ & \\
\hline
\end{tabular}

Sumber: Data Primer 2018 
Tabel. 5 Pelayanan Kesehatan

Penilaian Pelayanan Kesehatan di PT Suri Tani Pemuka

\begin{tabular}{|c|c|c|}
\hline \multirow{2}{*}{ Aspek yang diamati } & \multicolumn{2}{|c|}{ Keberadaan } \\
\hline & Ada & Tidak ada \\
\hline Tersedia pelayanan kesehatan dasar pada karyawan & & $\sqrt{ }$ \\
\hline Melakukan medical checkup secara periodik bagi seluruh karyawan & & $\sqrt{ }$ \\
\hline $\begin{array}{l}\text { Pemeriksaan kesehatan yang tepat diberikan, misalnya penglihatan, } \\
\text { pendengaran, skrining serviks dan perawatan yang sesuai. }\end{array}$ & & $\sqrt{ }$ \\
\hline $\begin{array}{l}\text { Melembagakan kebijakan kesetaraan gender di tempat kerja untuk } \\
\text { melindungi dan mendukung perempuan atau kebijakan perlindungan } \\
\text { bagi kelompok rentan lainnya }\end{array}$ & & $\sqrt{ }$ \\
\hline $\begin{array}{l}\text { Perusahan bekerjasama dengan layanan kesehatan setempat untuk } \\
\text { membuat program tempat kerja yang sehat. }\end{array}$ & $\sqrt{ }$ & \\
\hline
\end{tabular}

Sumber: Data Primer 2018 